\title{
ENTRE O MEDO DA CONTAMINAÇÃO PELO HIV E AS REPRESENTAÇÕES SIMBÓLICAS DA AIDS : O ESPECTRO DO DESESPERO CONTEMPORÂNEO
}

Paolo Meneghin*

MENEGHIN, P. Entre o medo da contaminação pelo HIV e as representaçōes simbólicas da AIDS: o espectro do desespero contemporaneo. Rev.Esc.Enf.USP,v.30, n.3, p. 399-415, dez. 1996

Este estudo pretende colaborar para uma melhor compreensão dos sentimentos provocados no ser humano vivendo em plena era da AIDS. A falta de informação e, por consequência, o desconhecimento sobre a AIDS, sua dinâmica de transmissão $e$ as medidas preventivas adequadas, transformam a convivência com esta sindrome num fator estressante para muitas pessoas, gerando sentimentos de medo e suscitando a correlação com diferentes representações simbólicas ligadas à contaminação pelo HIV. Vários autores formularam modelos teóricos para explicar esta correlação. Neste trabalho procura-se verificar os sentimentos emergentes e a respectiva vinculação aos significados simbólicos da doença sob o prisma destas teorias. Foram entrevistadas 31 pessoas, sendo 10 estudantes de diferentes cursos superiores da Universidade de São Paulo e 21 detentos do Sistema Penitenciário do Estado de São Paulo. Os resultados obtidos mostraram que, apesar dos grupos apresentarem caracteristicas diferentes entre si, ambos atribuiram à AIDS significados simbólicos ligados ao medo da contaminação pelo HIV.

UNITERMOS: AIDS. Assistência de enfermagem. Educação em Saúde.

\section{1 - INTRODUÇÃO}

$O$ aparecimento da síndrome de imunodeficiência adquirida - AIDS/SIDA - a partir do início dos anos 80, e a contínua disseminação do vírus da imunodeficiência humana - HIV - na última década, persistindo até os dias de hoje, originou, no mundo todo, respostas de ordem emocional, como o medo da contaminação pelo HIV. ${ }^{10}$

* Enfermeiro. Professor Doutor do Departamento de Enfermagem Médico-Cirúrgica da Escola de Enfermagem da Universidade de Săo Paulo. Membro do Núcleo de Pesquisas em Epidemiologia da AIDS - NUPAIDS - da Universidade de São Paulo. Membro do Núcleo de Estudos sobre Orientaça de Enfermagem ao Cliente Adulto - PRO.CLAD. 
A partir dos primeiros casos registrados, a AIDS alastrou-se rapidamente por todos os continentes como verdadeira pandemia, de elevado índice de letalidade, causando um verdadeiro estado de pânico entre a população. ${ }^{15}$

Este sentimento surge no momento em que as pessoas identificam a AIDS como uma séria ameaça à integridade física e a própria vida.

Por ser entidade nosológica recente a AIDS recebeu, por parte da mídia, os mais variados enfoques, desde a divulgação de novas descobertas científicas ao anedotário sensacionalista caracterís tico dos meios massivos de comunicação, abordando o tema de forma pejorativa, preconceituosa e, na maioria das vezes, contraditoria. ${ }^{15}$.

Em meio a este cenário de confusão e divergências, a ignorância e a desinformação sobre a AIDS foram um legado prejudicial a comunidade que continua desinformada, principalmente pela ausência de programas educativos sobre esta síndrome. Tal situação é responsável pelo aparecimento da um sentimento de impotência e insegurança definido como o espectro do desespero contemporâneo. ${ }^{10,14,15}$

A falta de conhecimento sobre a AIDS associada à forma geralmente preconceituosa de se encarar este problema leva as pessoas a expressar, de formas as mais variadas, seus sentimentos em relação a esta síndrome.

As informações incompletas e deturpadas veiculadas pelos meios de comunicaşão de massa, aliadas ao fato que a AIDS é uma doença sexualmente transmissivel, sem cura até o momento, evoca crenças e valores relacionados à sexualidade, ao uso de drogas e à morte como castigo, contribuindo para que as pessoas desenvolvam, com diferentes manifestações e intensidades, um sentimento de medo irracional quanto à contaminação pelo HIV. 10,12,14,20

Alguns modelos téricos procuram explicar o surgimento deste sentimento de medo que as pessoas desenvolvem em relação à AIDS, fazendo uma integração das teorias cognitivas, psicoanalíticas e fisiologicas da tensão e do "stress " que, segundo seus autores, provém de um estímulo ambiental percebido como sendo superior aos mecanismos de adaptação do indivíduo. 10,19,20

O medo do contágio da AIDS é visto como uma ameaça à integridade física do ser humano desencadeando operações mentais de memória, códigos, signos, símbolos abstratos e a formação de conceitos individualizados. Esta atividade neurocognitiva resulta em uma resposta afetiva expressa pelo sentimento do medo, como apresentado na Figura 1. 


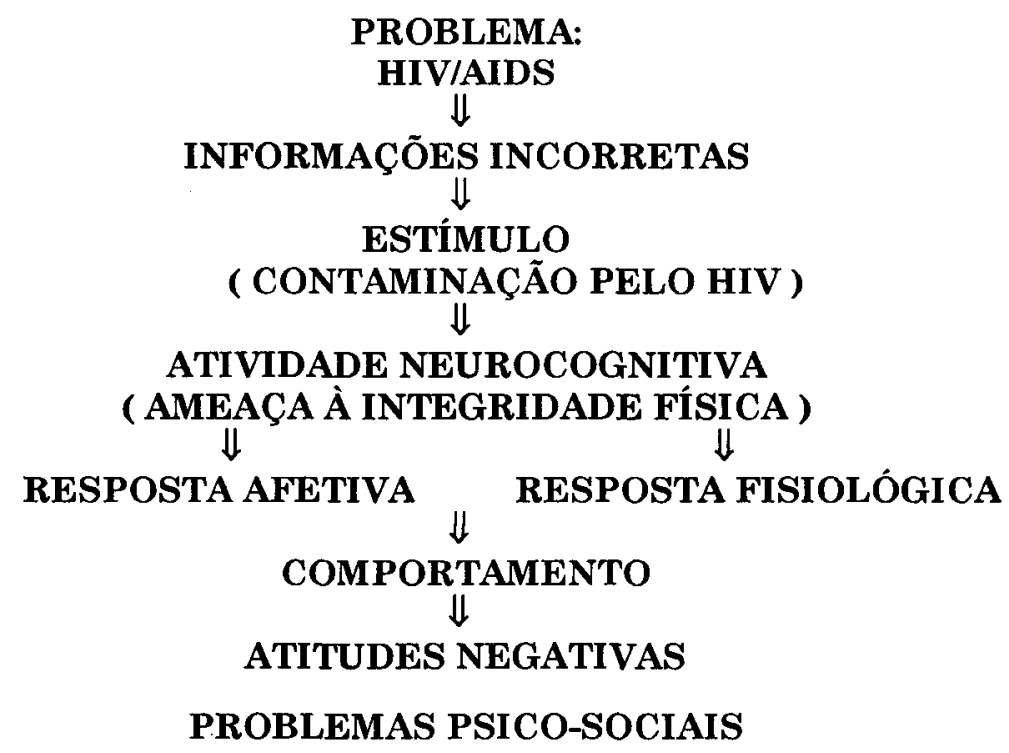

Figura 1. O medo como resposta a um fator estressante. ${ }^{7,19}$

O medo do contágio pelo HIV, portanto, não percorre os caminhos da evidência científica sobre a doença, mas perpassa pelos meandros dos valores individuais e das crenças da população evidenciando os significados simbblicos da doença, ligados intimamente à contaminação.As representações simbólicas mais ligadas a essa doença contagiosa são: o mistério, a punição e a morte. Portanto, de acordo com as crenças populares, quanto mais misteriosa for uma doença, mais ela será percebida como contagiosa e mais causará medo. ${ }^{10}$

A AIDS, por ser uma doença recentemente descoberta, representa o medo do desconhecido, a incerteza e faz emergir preconceitos associando-a aos tabus e crendices ainda existentes em relação à sexualidade que, como punição, pode levar à morte.

A ignorância, a desinformação, a ausência de programas educativos reforçam, ainda mais, as crendices e as superstições levando os indivíduos a adotarem, muitas vezes, precauções excessivas e desnecessárias que interferem negativamente em sua qualidade de vida. ${ }^{6}$

Esta situação desencadeia, nas pessoas, mecanismos que culminam com comportamentos de rejeição e atitudes discriminatórias que são demonstradas através da expressão de vários sentimentos.

Estas considerações podem ser esquematizadas como apresentadas na Figura 2. 
HIV / AIDS

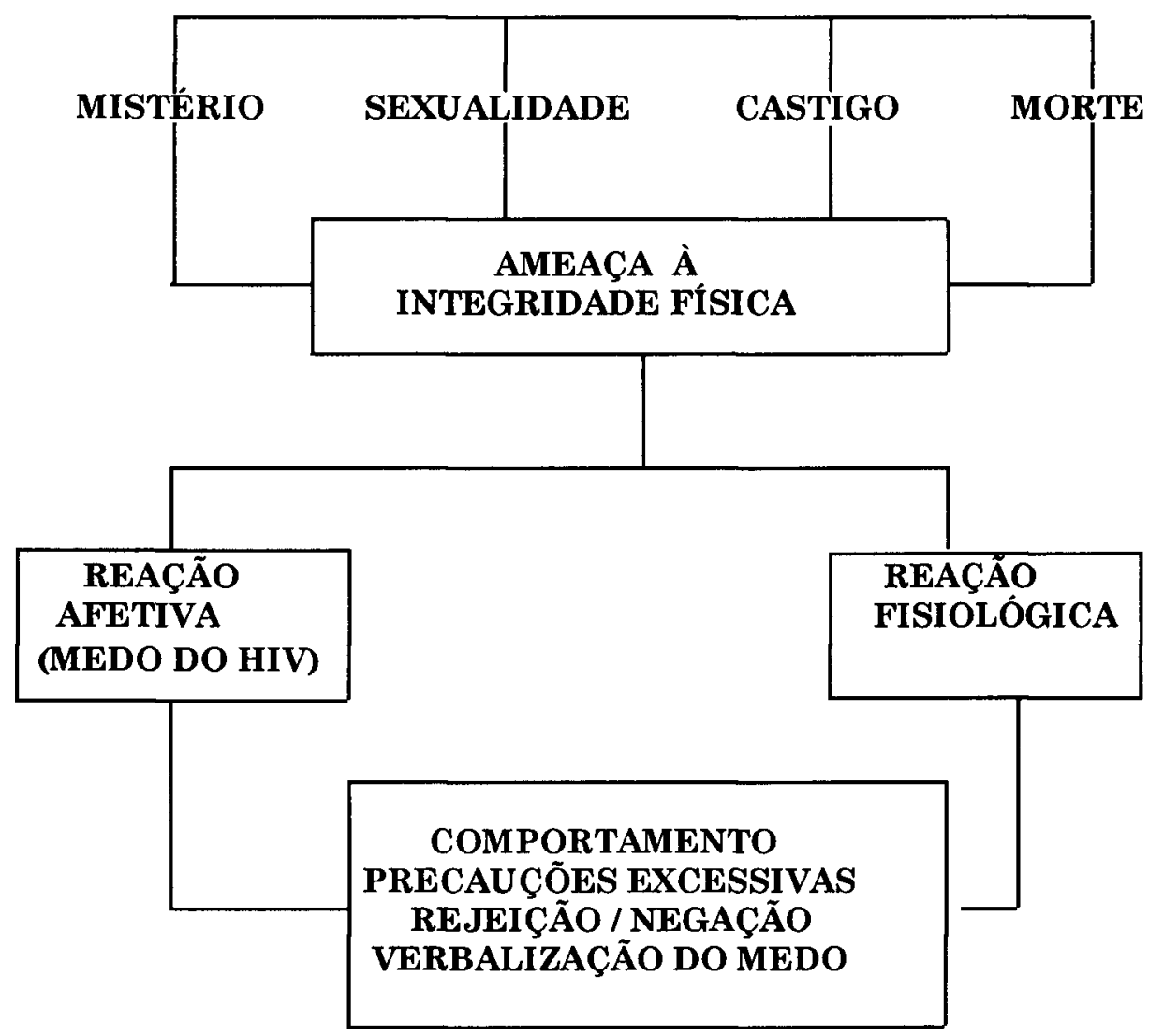

Figura 2. A AIDS como fator estressante no desenvolvimento do medo. ${ }^{10,11,19}$

Por entender que a AIDS representa uma metáfora repudiada por todos, a atividade neurocognitiva do ser humano percebe o HIV como uma ameaça à vida sob o prisma das representações simbólicas ligadas a esta doença. ${ }^{10}$

Quanto mais a doença suscita representações simbólicas, maior é a resposta afetiva do medo da contaminação pelo HIV. Situaçōes relacionadas com este sentimento já foram descritas e analisadas, mormente no que se refere ao trabalho dos profissionais da área de saúde. ${ }^{8,13,20}$

Outros trabalhos e pesquisas analisaram sentimentos e intenções de comportamento de trabalhadores em relação a companheiros HIV positivos em situações hipotéticas. ${ }^{10,11,12,15,22}$

Embora nestes trabalhos muito se tenha discorrido sobre o medo que a AIDS provoca e sobre as teorias que explicam o surgimento deste sentimento, os 
estudos geralmente se referem a situações imaginárias onde os pesquisadores levam os participantes a prever possiveis atitudes relacionadas a pessoas HIV positivas e descrever suas prováveis intenções de comportamento em relação aos portadores do vírus.

Os resultados destes estudos já demonstraram haver altos índices de rejeição, precauções exageradas e desnecessárias, medo e "homofobia" em relação à doença e aos doentes. ${ }^{7,8,10,15,22}$

Neste trabalho pretende-se apresentar os resultados de um estudo sobre as percepções e os sentimentos ligados às representações simbólicas provocadas pela AIDS com pessoas que, voluntariamente, se submeteram ao teste para deteç̧ão de anticorpos anti-HIV.

Numa tentativa de colaborar para um melhor entendimento dos comportamentos decorrentes do enfrentamento com a realidade HIVIAIDS e com a finalidade de aplicar e testar os modelos tebricos que explicam o surgimento do medo e sua ligaşão com os significados simbólicos desta doença, foi realizado este estudo tendo como objetivas:

- verificar como os participantes deste estudo perceberam a realidade HIV/AIDS em suas vidas, e

- identificar as representações simbólicas relacionadas ao medo da contaminação pelo HIV.

\section{2 - METODOLOGIA}

Este trabalho, de natureza exploratório-descritiva, foi realizado paralelamente ao desenvolvimento dos projetos de pesquisa efetuados pelo Núcleo de Pesquisas em Epidemiologia da AIDS - NUPAIDS - da Universidade de São Paulo para verificar fatores de risco e dinâmica de transmissão do HIV entre estudantes universitários* e entre presidiários** no Município de São Paulo entre os anos de 1993 e 1994 . Tais projetos previam coleta de sangue e respostas a um questionário sobre comportamento de risco por parte das pessoas que aceitassem participar do estudo.

Para colheita de dados do presente estudo foram realizadas 31 entrevistas ocasionais ${ }^{* * *}$ com os participantes - 10 estudantes universitários e 21 detentos - dos quais havia sido coletado sangue para detecção de anticorpos anti-HIV.

As entrevistas foram realizadas durante o período de espera dos resultados do referido exame, em ambiente privativo, para as pessoas que voluntariamente quisessem participar deste estudo.

\footnotetext{
* Projeto de pesquisa "Transmissão do HIV entre estudantes da Universidade de São Paulo: análise das práticas de risco, da prevalência e da dinânima da infeç̧ão, do nível de informa ção e do impacto de uma estratégia de intervenção". NUPAIDS - USP

** Projeto de pesquisa: "Interaçăo entre AIDS e tuberculose em popula çăo confinada: dinámica da transmissão e validação do critério tuberculose na definiçăo de AIDS ". NUPAIDS - USP

*** Para as entrevistas o Autor contou com a colaboração da psić́loga Leila Strazza - CRP 43419 .
} 
Aos que concordavam em participar da entrevista era assegurado o anonimato e garantido que suas informações seriam utilizadas unicamente em pesquisa.

Durante a entrevista procurava-se obter a descrição por parte do entrevistado, dos sentimentos e das reflexões relacionadas ao HIV/AIDS que emergiram durante o tempo de espera do resultado do exame de sangue.

O formulário utilizado como instrumentopara colheita de dados compunhase de duas partes: identificação da população participante, sem necessidade de nominação e questões abertas sobre os sentimentos provocados pela AIDS e as reflexões feitas sobre esta realidade após a coleta de sangue. As perguntas, para facilitar e estimular a expressão do entrevistado foram: "A AIDS é algo próximo ou distante de você?? " e "Como têm sido estes dias após colher o sangue?".

\section{3 - ANÁLISE DAS RESPOSTAS}

As respostas dadas pelos entrevistados a primeira pergunta foram analisadas de acordo com a categorização dos aspectos míticos relacionados com o HIV/AIDS descritos por MEISENHELDER (1994). ${ }^{12}$

Os sentimentos expressos pelos participantes por ocasião da segunda pergunta foram agrupados de acordo com as respostas afetivas provocadas pelo HIV/AIDS ,como agente estressor, relacionadas por MEISENHELDER ; La CHARITÈ (1989)..$^{10}$

Para apresentação dos dados deste estudo foram elaboradas tabelas para cada grupo de participantes, tanto para o perfil demográfico como para as manifestações de sentimentos.

As Tabelas 1 e 2 sumarizam as características demográficas dos grupos.

TABELA 1. CARAC'TERÍSTICAS DEMOGRÁFICAS DA POPULAÇÃO UNIVERSITÁRIA. SÃO PAULO, 1994.

\begin{tabular}{ccc}
\hline \multicolumn{1}{c}{ VARIÁVEIS } & $\mathbf{N}$ & $\%$ \\
\hline SEXO & & \\
MASCULINO & 6 & 60,0 \\
FEMININO & 4 & 40,0 \\
IDADE & & 10,0 \\
15 - 19 & 1 & 50,0 \\
$20-24$ & 5 & 30,0 \\
$\mathbf{2 5}-\mathbf{2 9}$ & 3 & - \\
$\mathbf{3 0}-\mathbf{3 4}$ & - & $\mathbf{1 0 , 0}$ \\
$\mathbf{3 5}-\mathbf{3 9}$ & 1 & - \\
$\mathbf{4 0}-\mathbf{4 4}$ & - & - \\
ESCOLARIDADE & & - \\
$\mathbf{1}^{\circ}$ GRAU & - & 100,0 \\
$2^{\circ}$ GRAU & - & \\
$\mathbf{3}^{\circ}$ GRAU & 10 & \\
\hline
\end{tabular}


Foi observado, também que a média de permanência dos participantes na universidade foi de 3 anos e 9 meses.

TABELA 2. CARACTERÍSTICAS DEMOGRÁFICAS DA POPULAÇÃO CARCERÁRIA. SÃO PAULO, 1994.

\begin{tabular}{ccc}
\hline \multicolumn{1}{c}{ VARIÁVEIS } & $\mathbf{N}$ & $\%$ \\
\hline SEXO & & \\
MASCULINO & 21 & $\mathbf{1 0 0 , 0}$ \\
FEMININO & - & - \\
IDADE & - & - \\
$\mathbf{1 5}-\mathbf{1 9}$ & $\mathbf{8}$ & $\mathbf{4 0 , 0}$ \\
$\mathbf{2 0}-\mathbf{2 4}$ & 5 & 25,0 \\
$\mathbf{2 5}-\mathbf{2 9}$ & 4 & $\mathbf{1 5 , 0}$ \\
$\mathbf{3 0}-\mathbf{3 4}$ & 1 & $\mathbf{5}, 0$ \\
$\mathbf{3 5}-\mathbf{3 9}$ & 3 & $\mathbf{1 5 , 0}$ \\
40 - 44 & & $\mathbf{8 0 , 0}$ \\
ESCOLARIDADE & 16 & $\mathbf{1 5 , 0}$ \\
$\mathbf{1}^{\circ}$ GRAU & 4 & $\mathbf{5 , 0}$ \\
$\mathbf{2}^{\circ}$ GRAU & 1 & \\
$\mathbf{3}^{\circ}$ GRAU & & \\
\hline
\end{tabular}

Nesta população o cálculo da média de permanência na casa de detenção foi de 3 anos e 8 meses.

As grandes diferenças entre os grupos dizem respeito à escolaridade e ao gênero. Somente homens foram entrevistados na penitenciária por ter sido realizada a pesquisa na ala masculina do presídio.

A variável "idade", no entanto, traz bastante proximidade entre os grupos quando se verifica que $80,0 \%$ dos estudantes situam-se na faixa etária entre 20 e 29 anos e, também, 80,0\% dos detentos estão na faixa etária entre 20 e 34 anos.

O perfil dos entrevistados, portanto, pode ser caracterizado como um grupo de adultos jovens e com média de permanência semelhante em ambas instituições, mas com diferentes níveis de escolaridade, podendo-se inferir, também, que os grupos possam apresentar diferentes níveis sócio-econômicos e projetos de vida diferenciados.

As características peculiares dos grupos poderão ser evidenciadas com a análise das respostas pertinentes à primeira indagação: " A AIDS é algo próximo ou distante de você ? porquê ?'.

Estas respostas puderam ser agrupadas em quatro categorias ou aspectos "míticos", já identificados por vários autores que evidenciam idéias errôneas e preconceitos em relação d̀ AIDS : 1,12,15,21,23

$1^{0}$. mito: a AIDS s 6 atinge homossexuais, prostitutas e usuários de drogas; 
$2^{0 .}$ mito: com pessoas conhecidas não precisa usar preservativo;

$3^{\circ}$. mito: a AIDS só acontece com os outros;

$4^{0}$ mito: a AIDS pode se transmitir pela proximidade com pessoas infectadas pelo HIV.

Os participantes consideraram a AIDS algo próximo ou distante tendo como referência as causas acima categorizadas e agrupadas de acordo com estes "mitos" nas Tabelas 3 e 4.

TABELA 3. DISTRIBUIÇÃO DAS OPINIÕES DOS UNIVERSITÁRIOS DE ACORDO COM AS CATEGORIAS APRESENTADAS. SÃO PAULO, 1994.

\begin{tabular}{|c|c|c|c|c|c|c|}
\hline \multirow[t]{2}{*}{ OPINIÕES* } & \multicolumn{2}{|c|}{ A AIDS ESTÁ LONGE } & \multicolumn{2}{|c|}{ A AIDS ESTÁ PERTO } & \multicolumn{2}{|c|}{ TOTAL } \\
\hline & $\mathbf{N}$ & $\%$ & $\mathbf{N}$ & $\%$ & $\mathbf{N}$ & $\%$ \\
\hline $\begin{array}{l}\text { 1. AIDS é doença de homossexuais, } \\
\text { prostitutas e usuários de drogas }\end{array}$ & 4 & 23,5 & $2^{* *}$ & 11,8 & 6 & 35,3 \\
\hline $\begin{array}{l}\text { 2. Com pessoas conhecidas não é } \\
\text { preciso usar preservativo }\end{array}$ & 4 & 23,5 & - & - & 4 & 23,5 \\
\hline 3. Comigo não vai acontecer & 4 & 23,5 & - & - & 4 & 23,5 \\
\hline $\begin{array}{l}\text { 4. O HIV se transmite pela proxi- } \\
\text { midade com pessoas infectadas }\end{array}$ & $1 * *$ & 5,9 & 2 & 11,8 & 3 & 17,7 \\
\hline TOTAL & 13 & 76,5 & 4 & 23,5 & 17 & 100,0 \\
\hline
\end{tabular}

* Porcentagens calcul adas sobre o totel de opinires emitidas pelos estudantes $(\mathrm{N}=17)$

* Respostas consider adas como comretas no contexto da entrevista

TABELA 4. DISTRIBUIÇÃO DAS OPINIÕES DOS DETENTOS DE ACORDO COM AS CATEGORIAS APRESENTADAS. SÃO PAULO, 1994.

\begin{tabular}{|c|c|c|c|c|c|c|}
\hline \multirow[t]{2}{*}{ OPINIÕES* } & \multicolumn{2}{|c|}{ A AIDS ESTÁ LONGE } & \multicolumn{2}{|c|}{ A AIIDS ESTÁ PERTO } & \multicolumn{2}{|c|}{ TOTAL } \\
\hline & $\mathbf{N}$ & $\%$ & $\mathbf{N}$ & $\%$ & $\mathbf{N}$ & $\%$ \\
\hline $\begin{array}{l}\text { 1. AIDS é doença de homossexuais, } \\
\text { prostitutas e usuários de drogas }\end{array}$ & 11 & 39,3 & $2^{* *}$ & 7,1 & 13 & 46,4 \\
\hline $\begin{array}{l}\text { 2. Com pessoas conhecidas não é } \\
\text { preciso usar preservativo }\end{array}$ & 5 & 17,9 & - & - & 5 & 17,9 \\
\hline 3. Comigo não vai acontecer & 2 & 7,1 & - & - & 2 & 7,1 \\
\hline $\begin{array}{l}\text { 4. O HIV se transmite pela proxi- } \\
\text { midade com pessoas infectadas }\end{array}$ & $1^{* *}$ & 3,6 & 7 & 25,0 & 8 & 28,6 \\
\hline TOTAL & 19 & 67,9 & 9 & 32,1 & 28 & 100,0 \\
\hline
\end{tabular}

* Porcentagens calcul adas sobre o totel de opinides emitides pelos estudentes ( $\mathrm{N}=28)$

* Respostes consideredas como corretes no contexto da entrevista 
Confirma-se, com estes resultados, que o estigma e os preconceitos sobre a AIDS ainda são sentimentos profundamente arraigados entre a população pois $39,9 \%$ das opiniões emitidas pelos detentos e $23,5 \%$ pelos estudantes deixaram entrever a presença deste mito, ainda forte, que percebe a AIDS como doença característica de alguns grupos. 5,7,10,14,16,17

Algumas das opiniões ilustram claramente este sentimento de se achar distante da doença por acreditar neste mito:

"..esta longe de mim porque é so deixar de transar com 'bicha' que não tem problema..."

"Prá mim não tem perigo porque não me relaciono com homossexuais nem com prostitutas.."

"... está muito longe porque não ando com 'bicha' de cadeia."

Apenas 2 estudantes $(11,8 \%)$ e 2 detentos $(7,1 \%)$ analisaram de forma correta sua proximidade com a doença por considerarem que seu estilo de vida poderia envolver comportamento de risco na medida em que se relacionaram com múltiplos parceiros ou fizeram uso de drogas sem se preocuparem com os cuidadados e as precauções necessárias.

Sabe-se, já há algum tempo, que não existe mais "grupo de risco" mas " pessoas com comportamento de risco". Considerar que a AIDS ainda se restringe a alguns grupos minoritários e estigmatizados é, no mínimo, colocar em risco a propria segurança e integridade física. Verifica-se, no entanto, que esta crença ainda persiste entre a população estudada.

Quanto ao segundo mito, alguns autores mostraram, em estudos realizados sobre crenças e valores, que grande contingente de pessoas é resistente ao uso de preservativo como forma de prevenção contra a AIDS e outras doenças sexualmente transmissiveis, apresentando as mais diversas razões para não adotar tal precaução. ${ }^{214,21}$ Neste trabalho, a presença deste segundo mito revela que, muitas vezes, as crenças sobrepujam as evidências científicas sobre os modos de transmissão.

O levantamento das respostas dos participantes mostrou, pelas opiniões dos estudantes $(23,5 \%)$ e dos detentos $(17,9 \%)$ que ainda há pessoas que não vêem necessidade de utilizar preservativos quando as parceiros (as) são " pessoas conhecidas".

Segundo a expressão dos próprios entrevistados, nestes casos não há perigo de contaminação nem necessidade de usar camisinha pois:

"...as mulheres que eu transo, são conhecidas."

"As minhas mulheres... foram sem perigo, eu conhecia todas ."

"...não precisa (usar camisinha) porque eu tenho namorada e a gente sabe da vida de cada um".

"... eu penso que se tiver um parceiro fixo eu vou transar sem camisinha..." 
$\mathrm{Na}$ opinião dos entrevistados que assim se expressaram a AIDS, é algo distante pois se relacionam com pessoas conhecidas e, neste caso, a ausência do medo contaminação pelo HIV pode ser prejudicial e fatal. A literatura tem demonstrado que, ultimamente, o HIV está se disseminando através de relações heterossexuais, transmitido por parceiros conhecidos, como namorados (as), amantes e cônjuges. ${ }^{4.8}$

O grupamento relativo ao terceiro mito pode ser relacionado diretamente com as características da faixa etária da amostra estudada.

Pensar que a AIDS, ou outra doença qualquer de cunho fatal, não possa acontecer consigo é um enfrentamento de vida próprio de adultos jovens, marcados ainda pela cultura adolescente, cujas características incluem as sensações de invulnerabilidade e inconsequência.

Das opiniões emitidas pelos estudantes $(23,5 \%)$ e pelos detentos $(7,1 \%)$ percebe-se que, dentre os primeiros, o sentimento de poder, força e invulnerabilidade está mais evidenciado, talvez pelo fato de terem conseguido ingressar na vida acadêmica de uma das mais cobiçadas universidades do País.

Este sentimento se sobrepõe a qualquer situação que se contraponha como ameaça à integridade física e pode ser percebida por afirmações dos participantes do estudo, como:

"...é uma coisa de crença, tipo: comigo não vai acontecer..."

"Eu tenho quase certeza que meu teste vai ser negativo..."

"Eu não tenho medo de pegar AIDS...ela não existe prá mim..." mim..."

"Eu não tenho com que me preocupar... eu não penso em AIDS prá

\section{"Eu penso que não vou ter essa doença nunca! "}

Esta sensação de poder e força pode ser vista como uma barreira entre o comportamento de risco e a tomada de decisão por parte dos jovens em se proteger ou adotar hábitos de precaução para evitar a contaminação pelo HIV ou outras doenças sexualmente transmissiveis.

Finalmente, qunto ao quarto mito, verifica-se, pelas opiniões expressas pelos estudantes $(11,8 \%)$ e pelos detentos $(25,0 \%)$ que o medo de contrair o HIV aliado à falta de conhecimento sobre os modos de transmissão da doença, provoca o receio de contaminação pela simples proximidade a pessoas, familiares e amigos portadores do vírus.

Constata-se, portanto, neste estudo, que o medo provocado pelo contato ou proximidade a portadores do HIV não é exclusivo de pessoas de baixa escolaridade, mas compartilhado até por profissionais da área de saúde conforme o comprovam trabalhos já realizados $9,11,12,15,16,22,23$

Quanto a este aspecto, apenas uma opinião $(5,9 \%)$ dentre os estudantes e uma $(3,6 \%)$ dentre os detentos considerou afastado o perigo de contaminação 
pelo HIV pela proximidade a pessoas infectadas, pois os entrevistados demonstraram saber que essa não é a forma de transmissão da doença.

O que intriga na análise destas declarações são as contradições existentes entre crenças aliadas à informações incorretas que levam uma pessoa a considerar desnecessário o uso de preservativo ao se relacionar com parceiros "conhecidos" mas, ao mesmo tempo, teme a contaminação pela simples proximidade a um portador do HIV.

Neste panorama de desinformação e contradições, é possível prever que, sob o estímulo de um agente estressor, tal como a coleta de sangue, muitos sentimentos em relação ao HIV / AIDS emergissem, como foi possivel detectar pelo estudo das respos tas à segunda indagação: "como têm sido estes dias após colher o sangue? em que você pensou ou refletiu?"

Da análise das descrições feitas pelos entrevistados depreendeu-se que, embora a maioria das opiniões dos estudantes $(76,5 \%)$ e dos detentos $(67,9 \%)$ dar a entender que a AIDS era algo muito distante, o período ap6s a coleta de sangue foi emocionalmente traumático para a maioria que referiu, em maior ou menor intensidade, ter experimentado o sentimento de medo, como pode-se observar pela Tabela 5 .

TABELA 5. DISTRIBUIÇÃO DAS EXPRESSÕES DOS PARTICIPANTES RELATIVAS AO SENTIMENTO DE MEDO DO HIV / AIDS. SÃO PAULO, 1994.

\begin{tabular}{|c|c|c|c|c|c|c|}
\hline \multirow[b]{2}{*}{ GRUPOS } & \multicolumn{2}{|c|}{ VERBALIZADO } & \multicolumn{2}{|c|}{ NÃO VERBALIZADO } & \multicolumn{2}{|c|}{ TOTAL } \\
\hline & $\mathbf{N}$ & $\%$ & $\mathbf{N}$ & $\%$ & $\mathbf{N}$ & $\%$ \\
\hline Universitários & 5 & 50.0 & 5 & 50,0 & 10 & 100,0 \\
\hline Detentos & 15 & 71,4 & 6 & 28,6 & 21 & 100,0 \\
\hline TOTAL & 20 & 64.5 & 11 & 35,5 & 31 & 100,0 \\
\hline
\end{tabular}

Como já foi visto anteriormente, o medo se constitui num sentimento decorrente, muitas vezes, do desconhecimento e desinformação sobre a AIDS somado aos significados simbólicos da doença e da contaminação que perpassa os meandros dos valores individuais e das crenças da população. ${ }^{45,10}$

Do relato dos entrevistados é possível relevar expressões como:

"...estes dias (antes do resultado) está sendo uma ansiedade só!"

"...é um grande medo. Só de falar já dá medo!"

"Está um clima de desespero..."

"Quando lembro me causa medo... terror..."

"...dá um frio na barriga... um choque." 
"Depois de colher o sangue foi a fase mais dificil... foi horrivel, fiquei ansioso."

"Ter concordado ( com o exame ) me abalou muito!"

"Foi horrivel... passei a pensar sendo positivo e negativo..."

"Entrei em pânico depois de uns quinze dias do teste!"

"Foi a fase mais dificil... foi horrivel!"

Este estímulo, provocado pela coleta de sangue, levou os participantes deste estudo a diferentes reações em relação à doença como a reflexão sobre uma realidade próxima ou a negação e fuga do enfrentamento com esta mesma realidade, como pode ser observado na Tabela 6 .

TABELA 6. DISTRIBUIÇÃO DAS REACOÕES DOS PARTICIPANTES EM RELAÇÃO AO HIVIAIDS. SÃO PAULO, 1994.

\begin{tabular}{lcccccc}
\hline & REAÇŌES & \multicolumn{2}{c}{ NEGACÃO/FUGA } & \multicolumn{2}{c}{ ENFRENTAMENTO } & \multicolumn{2}{c}{ TOTAL } \\
GRUPOS & $\mathbf{N}$ & $\%$ & $\mathbf{N}$ & $\%$ & $\mathbf{N}$ & $\%$ \\
\hline Universitários & - & - & 10 & 100,0 & 10 & 100,0 \\
Detentos & 11 & 52,4 & 10 & 47,6 & 21 & 100,0 \\
\hline TOTAL & 11 & 35.5 & 20 & 64,5 & 31 & 100,0 \\
\hline
\end{tabular}

Pode-se notar que nenhum estudante "fugiu" do enfrentamento mental com a realidade da AIDS imposto pelo fator estressante do exame de sangue, enquanto, entre os detentos a maioria não conseguiu fazê-lo. Dentre as respostas que demonstram tal atitude dos detentos encontram-se expressões como:

"... não quis nem pensar..."

"Quando me lembro afasto o pensamento..."

"...nem pensei nisso e quando vem na mente eu "brigo" e não deixo ficar..."

"...quando vem qualquer pensamento sobre isso eu desvio, nem quero pensar..."

Quando a coleta de sangue para o teste deflagrou a atividade neurocognitiva dos estudantes, que caminham numa linha ascendente em relação ao seu consciente psíquico, percebe-se que eles repensam suas vidas e seus comportamentos levados pelo medo real do objeto receado, ou seja, pelo medo da possibilidade de terem se contaminado com es te objeto. ${ }^{18}$ 
Como resposta observa-se uma reação mental elaborada, onde seus projetos de vida são repensados, encurtando-os ou tentando vivê-los nopresente, tomando consciência dos comportamentos inadequados adotados por eles até então. Esta elaboração pode ser percebida quando os estudantes se expressaram:

"...fiquei pensando se fosse positivo...tinha que buscar meus ideais, minhas coisas e tinha que ser imediatamente."

"...eu teria que conhecer o que não tinha conhecido ainda..."

"Teria que abandonar projetos a longo prazo e buscar projetos mais imediatos..."

"O que vou fazer se tiver AIDS? ... aproveitar a vida nos próximos 5 ou 10 anos... me dedicar a escrever contos..."

"Comecei a perceber, no meio do caminho, que as coisas que eu havia traçado, me imaginando positivo, eram muito mais interessantes. E veio em mente: será que eu preciso ter AIDS para tomar decisões?..."

"O imaginário do positivo me fez ver que eu precisava mudar o rumo de minha vida..."

Por outro lado, quando foi estimulada a atividade neurocognitiva dos detentos, a maioria $(52,4 \%)$ preferiu não pensar, provavelmente por não saber trabalhar com seus conteúdos ansígenos ou por falhas ocorridas em seu processo educativo. ${ }^{3}$ Os que repensam em suas vidas $(47,6 \%)$ o fazem primordialmente sob a ótica das crenças e dos significados simbólicos que a AIDS desperta em suas mentes.

As pesquisas que se referem às reações que a AIDS causa nas pessoas, esquematizadas na introdução deste estudo, evidenciam que a transmissão de doenças misteriosas ou desconhecidas, ligada a comportamentos considerados anti-sociais ou reprováveis e passíveis de sanções, está também vinculada a representações simbólicas como a punição, o castigo divino e a morte.

Neste estudo também foi encontrada esta correlação como se observa na Tabela 7.

TABELA 7. DISTRIBUIÇÃO DAS REPRESENTAÇÕES SIMBÓLICAS REFERIDAS PELOS PARTICIPANTES RELACIONADAS A CONTAMINAÇÃOO PELO HIV. SÃO PAULO, 1994.

\begin{tabular}{|c|c|c|c|c|c|c|c|}
\hline \multirow[b]{2}{*}{ GRUPOS } & \multirow{2}{*}{$\begin{array}{c}\text { REPRESENTAÇÕES } \\
\text { SIMBÓLICAS }\end{array}$} & \multicolumn{2}{|c|}{ PUNICĀO/CASTIGO } & \multicolumn{2}{|c|}{ MORTE } & \multicolumn{2}{|c|}{ TOTAL } \\
\hline & & $\mathbf{N}$ & $\%$ & $\mathbf{N}$ & $\%$ & $\mathbf{N}$ & $\%$ \\
\hline Universitários & & 4 & 40,0 & 6 & 60,0 & 10 & 100,0 \\
\hline Detentos & & 19 & 90,5 & 2 & 9,5 & 21 & 100,0 \\
\hline TOTAL & & 23 & 74,2 & 8 & 25,8 & 31 & 100,0 \\
\hline
\end{tabular}


O simbolismo da punição tem mais espaço no processo psíquico dos detentos $(90,5 \%)$ que no dos estudantes $(40,0 \%)$ gerando a desesperança e o desalento.

Encarcerados simbolicamente desde a infância pelos problemas psico-sócioculturais e encarcerados no momento presente pela lei, tornam-se incapazes de pensar num processo de transformação de vida. ${ }^{3}$ () estudante faz planos, transforma o objeto do medo. (O detento tem medo de continuar sendo "preso" pela AIDS. Ele verbaliza a crença de que nunca será digno do perdão divino por se considerar um desviante social. Ele considera que não merece o perdão nem de Deus nem da sociedade porque matou, traficou, assaltou, estuprou, usou drogas e, por isso, vai continuar sendo um "preso".

$O$ detento não vê possibilidades, na prisão, de iniciar um processo educativo sobre si mesmo e não acredita que a sociedade lhe dará oportunidades para crescer e se redimir. Portanto, considera que, se for HIV positivo será uma punição divina justa, principalmente para quem adquiriu a doença por relação sexual promíscua ou uso de drogas.

O significado simbólico da punição, ligado sobretudo à sexualidade e promiscuidade, faz com que o detento apresente uma resposta de conformismo:

"Se eu tiver AIDS tem mais gente que está com isso e eu não sou melhor que ninguém..."

"... se eu for positivo... é aquela coisa de pensar no castigo divino, de ter sido escolhido por Deus por aquilo que eu fiz..."

Serem positivos, neste momento de suas vidas talvez os façam eximir-se das culpas de seus atos. Foi possível observar, na locução de alguns detentos, até uma ponta de fantasia elaborando, eles mesmos, outras formas de punição:

"... eu pensei até no Governo tentando passar uma 'overdose' de AIDS (por ocasião da coleta de sangue) aqui na Detenção para combater o crime... ia ser fácil... ninguém ia saber."

Essa elaboração simbólica sobre o medo da punição talvez possa explicar o fato dos estudantes refletirem mais sobre a dualidade vida-morte.

Os estudantes ligam a doença ao simbólico da morte (60,0\%) demonstrando que o agente ansígeno os levou a uma reflexão sobre a própria vida, seus comportamentos muitas vezes inadequados e de alto risco como a falta de proteção ou a multiplicidade de parceiros na relação sexual e o uso de drogas injetáveis.

Alguns estudantes chegaram a se imaginar positivos e se surpreenderam fazendo uma recomposição e adaptação em seus ideais de vida:

"...eu largaria o emprego e os estudos, se fosse positivo, para ter mais tempo livre e ficar com meu filho..."

" Foi ótimo me imaginar positiva. Coloquei algumas coisas em execução imediatamente quando me deparei com a possibilidade da morte..." 
Para os estudantes, o imaginário de ser HIV positivo, ligado ao simb6lico da morte, fez com que muitos deles mudassem comportamentos, tomassem decisões pelo fato de, ainda que de modo fictício, terem percebido a morte como um evento muito proximo e real.

A perda da vida, para os detentos é fatalidade e castigo merecido, não havendo o que modificar. Para os estudantes, a morte também é fato inexorável mas, ao mesmo tempo, é força motriz para gerar modificações e executar projetos possiveis.

\section{CONCLUSÕES}

A AIDS e ainda uma doença cercada por mitos e crenças que, na maioria das vezes, se constituem verdadeiras barreiras para permitir mudanças significativas de comportam ento e adoção de hábitos preventivos para bloqu ear a disseminação do HIV.

Este estudo, mesmo que limitado, espera poder contribuir para evidenciar que o enfrentamento do HIV/AIDS por parte das pessoas é uma situação estressante que desencadeia respostas afetivas importantes.

Apesar de os participantes pertencerem a grupos diferentes em vários aspectos, ambos apresentaram reações provocadas pela atividade neurocognitiva face à possibilidade de contaminação pelo HIV.

A maioria dos entrevistados $(67,9 \%)$ considerou a AIDS como uma realidade distante e fora de suas vidas, fundamentando-se em aspectos míticos que comprovam a persistência de idéias errôneas e preconceituosas sobre a doença.

Apesar desta aparente tranquilidade, $64,5 \%$ dos respondentes verbalizaram ter experimentado o sentimento de medo; $64,5 \%$ relataram que o fato de se submeterem, ainda que voluntariamente, ao teste para deteção de anticorpos anti-HIV, levou-os a refletir sobre seu estilo de vida e que estas reflexões foram feitas com base nas representações simbólicas relacionadas à punição e castigo divino $(74,2 \%)$ e à morte $(25,8 \%)$.

\section{CONSIDERAÇÕES FINAIS}

Pairam muitas sombras, ainda, sobre a existência do ser humano vivendo em tempos de AIDS, a única doença sexualmente transmissível sem cura até o momento.

Os dados obtidos neste estudo, longe de serem conclusivos, serviram, entre outras coisas, para mostrar que a discussão sobre a AIDS não pode se limitar 
aos aspectos fisiopatológicos da doença, mas deve se ampliar e aprofundar também nos aspectos emocionais e seus reflexos nos sentimentos e comportamentos das pessoas.

Estes aspectos devem ser considerados pelos enfermeiros, como educadores em saúde, ao formularem programas educativos sobre a AIDS.

Os mitos, as crenças, os valores e as representações simbólicas decorrentes do enfrentamento com a disseminação do HIV são elementos básicos que o educador precisa levar em conta ao elaborar os conteúdos de programas de educação em saúde.

MENEGHIN, P. Living between fear of contagion and the symbolic meanings of HIV/AIDS: shadow of contemporary hopelessness. Rev.Esc.Enf.USP. v.30, n.3, p. 399-415, dec. 1996.

Lack of knowledge and misinformations on HIV/AIDS are predictors of emotional responses as fear of contagion, homophobia, avoidance and excessive precautions. Fear of contagion is an affective stress response to the neurocognitive activity that leads to a perceived threat of AIDS in connection with the symbolic meanings os illness. Focused interviews were conducted with an opportunistic sample of 31 young people to know the affective responses and behaviors after blood screening for HIV antibody testing. The findings confirm the relationship of symbolic representation of illness as mystery, death, punishment and sexuality to fear of contagion and mitic conception of AIDS.

UNITERMS: AIDS. Nursing care. Health education.

\section{REFERÊNCIAS BIBLIOGRÁFICAS}

1. BOUTON, R.A. et al. Scales for measuring fear of AIDS and homophobia. J.Personal Assessment, v.51, n.4, p.606-14, 1987.

2. CATANIA, J.A et al. Towards an understanding of risk behavior: an AIDS Risk Reduction Model (ARRM). Health Educ. Quart. , v.17, n.1, p.53-72, 1990.

3. DOURADO, L.A. Ensaio de psicologia criminal. Rio de Janeiro, Zahar, 1969.

4. FIRN, S.;NORMAN, I.J. Psychological and emotional impact of an HIV diagnosis. Nurs.Times, v.91, n8, p.37-9, 1995.

5. Nurses'role in supporting people who are HIV positive.

Nurs.Times, v.91, n.12, p.37-9, 1995.

6. FLASKERUD, J.H.;RUSCH, C.E. AIDS and traditional health beliefs and practices of black women. Nurs. Res. v.38, n.4, 1989.

7. HANSEN, B et al. Workers with AIDS: attitudes of fellow employees. AAOHN J, v. 36, n. 7, p.279.83, 1988. 
8. JEMMOTT III, J.B. et al. Perceived risk infection and attitudes toward risk groups: determinants of nurses'behavioral intentions regarding AIDS patients.

Res.Nurs. Health, v.15, n.4.p.295-301. 1992.

9. KOPFER,A.M.; MCGOVERN, P.M. Transmission of HIV via needlestick injury. AAOHN J, v.41, n.8, p.374-81, 1993.

10. MEISENHELDER, J.B.; LACHARITE. C.L. Fear of contagion: a stress response to acquired immunodeficiency syndrome. ANS. v. 11. n.2, p.29.38, 1989.

11. ___ RICE. L. Evaluating interventions for fear of contagion. JANAC, v.5, n.5, p.48-55, 1994

12. Contributing factors to fear of HIV contagion in registered nurses. IMAGE, v.26, n.1, p.65-9, 1994.

13. MENEGHIN, P. AIDS: assistência de enfermagem e revisão de literatura. Rev.Paul.Enf., v.6, n.3. p.99-107. 1986 .

14. __ et al. AIDS: uma crise de saúde (e comunicação) pública. /Apresentado ao Encontro Internacional Pesquisa em Enfermagem: uma questão de saúde. São Paulo, 1992/

15 O enfermeiro construindo e avaliando açoes educativas na prevença da AIDS. São Paulo, 1993. Tese (Doutorado) - Escola de Enfermagem. Universidade de São Paulo.

16. ;STEFANELLI. M.C.AIDS, mass media and health education./Apresentado aoFirst International Conference on Community Health Nursing Research. Alberta. Canada.1993.

17 MENENBERG, S.R. Somatopsychology and AIDS victims J.Psychol.Nurs., v.25, n.5,p.18$22,1987$.

18. SANDSTROM, C.I. A psicologia da infáncia e da adolescéncia. 2.ed. Rio de Janeiro. Zahar. 1969 .

19. SCOTT, D.W. et al. A stress-coping model. ANS. v.3, n.1, p.9-23. 1980.

20. SHEEHY, C.; TRUDEAU, V. AIDS education strategies: evaluating the fear response AAOHN J, v.40. n.6, p.271-8. 1992.

21. STRADER, M.K,; BEAMAN, M.L. Comparis on of selected college students'and sexually transmitted disease clinic patients'knowledge about AIDS, risk behaviours and beliefs about condom use. J.Adv. Nurs., v. 16, p.584-90, 1991.

22. TESSARO, I.: HIGHRITER. M. HIV and the work intentions of public health nurses. Pub.Health Nurs., v. 11, n.4, p.273-80, 1994.

23. WICHER, C.P. AIDS and HIV: the dilemma of the health care workers. AAOHN J., v.41, n.6, p.282-8, 1993 . 